\title{
O-GIcNAcylation in Hyperglycemic Pregnancies: Impact on Placental Function
}

\author{
Jie Ning ${ }^{1,2,3}$ and Huixia Yang ${ }^{1,2,3 *}$ \\ ${ }^{1}$ Department of Obstetrics and Gynaecology, Peking University First Hospital, Beijing, China, ${ }^{2}$ Beijing Key Laboratory of \\ Maternal Foetal Medicine of Gestational Diabetes Mellitus, Beijing, China, ${ }^{3}$ Peking University, Beijing, China
}

OPEN ACCESS

Edited by:

Stephen Atkin,

Royal College of Surgeons in Ireland,

Bahrain

Reviewed by:

Maria Mirabelli,

University Magna Graecia of

Catanzaro, Italy

Ee Phie Tan

Sanford Burnham Prebys Medical Discovery Institute, United States

Ewa Forma,

University of Łódź, Poland

*Correspondence:

Huixia Yang

yanghuixia@bjmu.edu.cn

Specialty section:

This article was submitted to

Systems Endocrinology,

a section of the journal

Frontiers in Endocrinology

Received: 16 February 2021

Accepted: 17 May 2021

Published: 01 June 2021

Citation:

Ning $J$ and Yang H (2021)

O-GICNAcylation in

Hyperglycemic Pregnancies:

Impact on Placental Function.

Front. Endocrinol. 12:659733.

doi: 10.3389/fendo.2021.659733
The dynamic cycling of $\mathrm{N}$-acetylglucosamine, termed as O-GlcNAcylation, is a posttranslational modification of proteins and is involved in the regulation of fundamental cellular processes. It is controlled by two essential enzymes, O-GlcNAc transferase and O-GlcNAcase. O-GlcNAcylation serves as a modulator in placental tissue; furthermore, increased levels of protein O-GlcNAcylation have been observed in women with hyperglycemia during pregnancy, which may affect the short-and long-term development of offspring. In this review, we focus on the impact of O-GlcNAcylation on placental functions in hyperglycemia-associated pregnancies. We discuss the following topics: effect of O-GlcNAcylation on placental development and its association with hyperglycemia; maternal-fetal nutrition transport, particularly glucose transport, via the mammalian target of rapamycin and AMP-activated protein kinase pathways; and the two-sided regulatory effect of O-GlcNAcylation on inflammation. As O-GlcNAcylation in the placental tissues of pregnant women with hyperglycemia influences near- and longterm development of offspring, research in this field has significant therapeutic relevance.

Keywords: O-GIcNAcylation, hyperglycemia in pregnancy, placental function, O-GIcNAc transferase, O-GINAcase

\section{INTRODUCTION}

Hyperglycemia in pregnancy (HIP), one of the most common medical conditions during pregnancy, may be classified as gestational diabetes mellitus (GDM) and diabetes mellitus in pregnancy. HIP is an important cause of adverse pregnancy outcomes and increasing incidences of metabolic syndromes in adulthood (1-3). The placenta is a key interface for maternal-fetal interaction, particularly for nutrition transport. It is instrumental in fetal intrauterine growth and long-term development of offspring. The placenta of women with HIP is exposed to a high concentration of blood glucose at different degrees and windows of time. This may affect numerous cellular pathways, leading to accumulation of advanced glycation end-products $(4,5)$ and induction of oxidative stress (6). The reported activation of the chronic hexosamine biosynthetic pathway (HBP) in placental tissue under similar conditions is also garnering attention (7).

O-linked $\beta$-N-acetylglucosamine (O-GlcNAc) glycosylation (O-GlcNAcylation) is a posttranslational modification (PTM) of proteins that plays an essential role in regulating various cellular processes (Figure 1). In contrast to classical N-/O-linked glycosylation, which mostly occurs in the Golgi compartment and endoplasmic reticulum with the extraordinarily extracellular 
complex array of glycans, the substrate for O-GlcNAcylation is uridine diphosphate $\mathrm{N}$-acetylglucosamine (UDP-GlcNAc) generated from HBP. HBP is a pathway that integrates glucose, fatty acid, amino acid, and nucleotide metabolism. The GlcNAc moiety from UDP-GlcNAc can be transferred onto the serine and threonine residues of a wide variety of nuclear, cytoplasmic, and mitochondrial proteins through the catalytic activity of the enzyme O-GlcNAc transferase (OGT). The cleavage of OGlcNAc from proteins is catalyzed by glycoside hydrolase OGlcNAcase (OGA) (also named MGEA5). Similar to other PTMs, this process is dynamic and reversible (7).

It has been reported that O-GlcNAcylation occurs in the placenta and is involved in transcriptional regulation, signal transduction, and epigenetic modifications (8-11). OGA is expressed in most tissues, and one of the highest expression was found in the placenta (12). OGT acts as a placental biomarker of maternal stress, which affects fetal neurodevelopment (13). Studies in diabetes mellitus have shown that hyperglycemia directly increases protein O-GlcNAcylation, at least in part, by increasing the glucose flux through HBP, and that OGT/OGA expression may be regulated by chronic hyperglycemia (14). Studies on hyperglycemic rat models have also shown that OGlcNAcylation levels increase in the placenta depending on the severity of hyperglycemia, and that trophoblast cells were the main target for O-GlcNAcylation (8). The focus of this review is to summarize the impact of O-GlcNAcylation in placenta exposed to HIP.

\section{PLACENTA GROWTH AND DEVELOPMENT}

The placenta is involved in the development, adaptation, and physiology of offspring in response to maternal growth and nutrient signals, primarily by regulating nutrient transport. OGlcNAcylation seems to be an important modulator during placentation and placental development (15) (Figure 2). Studies on mouse embryos have demonstrated that the nuclear localization of Yes-associated protein 1 (YAP1) is glucose/HBP/ O-GlcNAcylation-dependent, and this event is crucial for differentiation of the apical blastomeres to form the extraembryonic trophectoderm (TE) (16). During the incipient stages of trophoblast development at implantation, Ruane et al. (17) proposed that O-GlcNAcylation drives TE differentiation to the invasive trophoblast, as well as the differentiation of BeWo to syncytiotrophoblasts (STBs). Moreover, the O-GlcNAcylation of histone variant $\mathrm{H} 2 \mathrm{~A}$ was also shown to participate in the trophoblast stem cell differentiation process (18). A recent study on the placenta suggested that the O-GlcNAcylation of cystathionine $\gamma$-lyase (CSE) at Ser138 promotes its activity to produce $\mathrm{H} 2 \mathrm{~S}$. Further, $\mathrm{H} 2 \mathrm{~S}$ inhibits androgen receptor dimerization and then represses trophoblast syncytialization (19). Glutamine fructose-6-phosphate amidotransferase (GFAT), an important rate-limiting enzyme of the HBP, regulates trophoblast cell proliferation in response to glucose through phosphatidylinositol 3-kinase (PI3K)-independent mammalian target of rapamycin (mTOR) activation (20). Furthermore, autophagy, a process which is governs the degradation of misfolded proteins and damaged organelles, is important for normal placental developmental activities, such as invasion and vascular remodeling of extravillous trophoblasts (EVT). Studies on HTR8/SVneo cells showed that mTOR signaling also plays a role in regulating autophagy via the modulation of Beclin1 and synaptosome associated protein 29 (SNAP29) O-GlcNAcylation (21). Enhanced autophagy levels have been observed in human and mouse placentas exposed to HIP, as well as trophoblast cells in high-glucose environments (22-24). With regard to HIP, it is worth studying the exact function of the O-GlcNAcylation-associated regulation of autophagy in placental development.

Placental OGT and OGA expression levels both affect placental development; however, maternal stress seems to be the pivotal regulator of OGT and is more critical for fetal neurodevelopment, rather than hyperglycemia (13, 25-27). And, as an X-linked gene, placental OGT levels and its biochemical marker, O-GlcNAcylation are higher in females than in males. Male fetuses are associated with an increased risk of GDM in the mother $(28,29)$, and there might be an OGlcNAcylation-related sexual dimorphism in the placental response to maternal hyperglycemia. In contrast, the regulation of OGA expression is more associated with glycemia. Dela Justina et al. (8) observed that increased O-GlcNAcylation accumulation in placental tissue exposed to severe hyperglycemia might contribute to an increased placental index and morphometric alterations, which could be associated with placental dysfunction. Although there were no changes in OGT expression in all groups, OGA expression was augmented in placentas from the mild hyperglycemic group and reduced in placentas from hyperglycemic rats. This might be a biological compensation phenomenon as a result of being confronted with a mounting supply of glucose through HBP flux. Yang et al. (30) proposed that OGA deletion suppresses hypoxia-inducible factor-1 $\alpha$ (HIF-1 $\alpha$ ) stabilization and the transcription of its target genes, leading to impaired placental vasculogenesis and consequent disorders in fetal growth and development. The possible mechanism of $\mathrm{O}$ GlcNAcylation and OGT in the translation and stabilization of HIF- $1 \alpha$ has been studied in cancer cells. It was observed that an increased level of O-GlcNAcylation and the overexpression of OGT reduced $\alpha$-ketoglutarate, which assists hydroxylation and the degradation of HIF-1 $\alpha$ (31). Moreover, unbalanced OGlcNAcylation levels favor endothelial dysfunction in uterine arteries, which is important for uteroplacental circulation and this is partly modulated by OGT (32). These results might partly explain the structural and functional immaturity of placentas exposed to hyperglycemia and its effect on maternal-fetal interactions (33).

In addition to its influence on placenta, O-GlcNAcylation can directly affect embryonic development, including the regulation of oocyte meiotic division, embryo implantation and the survival and differentiation process of embryonic pluripotent stem cells. Besides, O-GlcNAcylation-related excessive induction of reactive oxygen species (ROS) and subsequent oxidative stress leads to embryo DNA damage, mitochondrial instability, and cell 
apoptosis (34-36). A recent study also emphasized that the $\mathrm{O}$ GlcNAc-dependent regulatory pathway is important for the DNA damage response required to maintain homeostasis in embryonic stem cells (37). Further, Muha et al. (38) proposed that the loss of OGA catalytic activity leads to widespread organ defects in mouse embryogenesis. Researchers have suggested that dysregulation of HBP and O-GlcNAcylation are major contributors toward the embryotoxic effects of hyperglycemia in early pregnancy (39). Another study also suggested that increased O-GlcNAcylation in metabolically compromised pregnancies, such as HIP, could be the underlying cause of defective neurodevelopmental outcomes (40).

\section{NUTRIENT SENSING}

The placenta contains an array of nutrient-sensing signaling pathways. Of these nutrient sensors, mTOR and AMP-activated protein kinase (AMPK) play a key role (41). Their involvement in placental O-GlcNAcylation is responsible for placental development and glucose and amino acid transport (42) (Figure 1).

The atypical serine/threonine kinase mTOR is part of two complexes with distinct functions and structures: mTOR complex 1 (mTORC1) and mTORC2 (43). mTORC1 is highly expressed in trophoblast cells (44). mTOR plays an important role in controlling trophoblast cell growth, proliferation, syncytialization and macropinocytosis (45). mTOR activity is regulated by the concentration of glucose, amino acids, and insulin, and is mediated by the PI3K/AKT signaling pathway. It stimulates cell growth through the phosphorylation of tuberous sclerosis complex 2 (TSC2), a negative regulator of mTORC1, and activation of Ras homolog enriched in brain (46, 47). mTORC1 promotes protein synthesis by directly phosphorylating the eukaryotic translation initiation factor $4 \mathrm{E}$ (eIF4E) binding protein 1 (4E-BP1) and ribosomal protein S6 kinase (p70S6K) (48). The activity of GSK3 $\beta$, an enzyme that regulates glycogen synthesis, is inhibited by the activation of insulin-AKT signaling pathway, which executes diverse biological functions (49). Besides, GSK3 phosphorylation of TSC2 inhibits the mTOR signaling pathway and the regulation requires AMPK activity (50). Dynamic changes in the AMP: ATP ratio regulate the activation of AMPK. In addition to participating in a variety of cellular activities such as lipid metabolism, AMPK targets the mTORC1 pathway, which plays a direct/indirect inhibitory role (51). Several participants of the $\mathrm{PI} 3 \mathrm{~K} / \mathrm{AKT} / \mathrm{mTOR}$ signaling pathway have been found to be modified by O-GlcNAcylation, such as IRS-1, PI3K, AKT, AMPK, p70S6K, 4E-BP1, and GSK3 $\beta$ (52-54).

Increased mTOR activity and decreased AMPK activity can be observed in placentas exposed to HIP (55-57). In a variety of tissues including the placenta, it has been proven that the expression, localization and activation of the key enzymes of O-GlcNAcylation are regulated by these nutrient-sensing signaling pathways. Studies on cardiomyocytes demonstrated that GFAT can be directly phosphorylated by AMPK, thereby reducing its activity and lowering O-GlcNAcylation levels (58). The localization, expression, and substrate specificity of OGT are regulated by AMPK, which is highly dependent on various factors such as the physiological/pathological status and cell types. In several pathologies, O-GlcNAcylation levels are

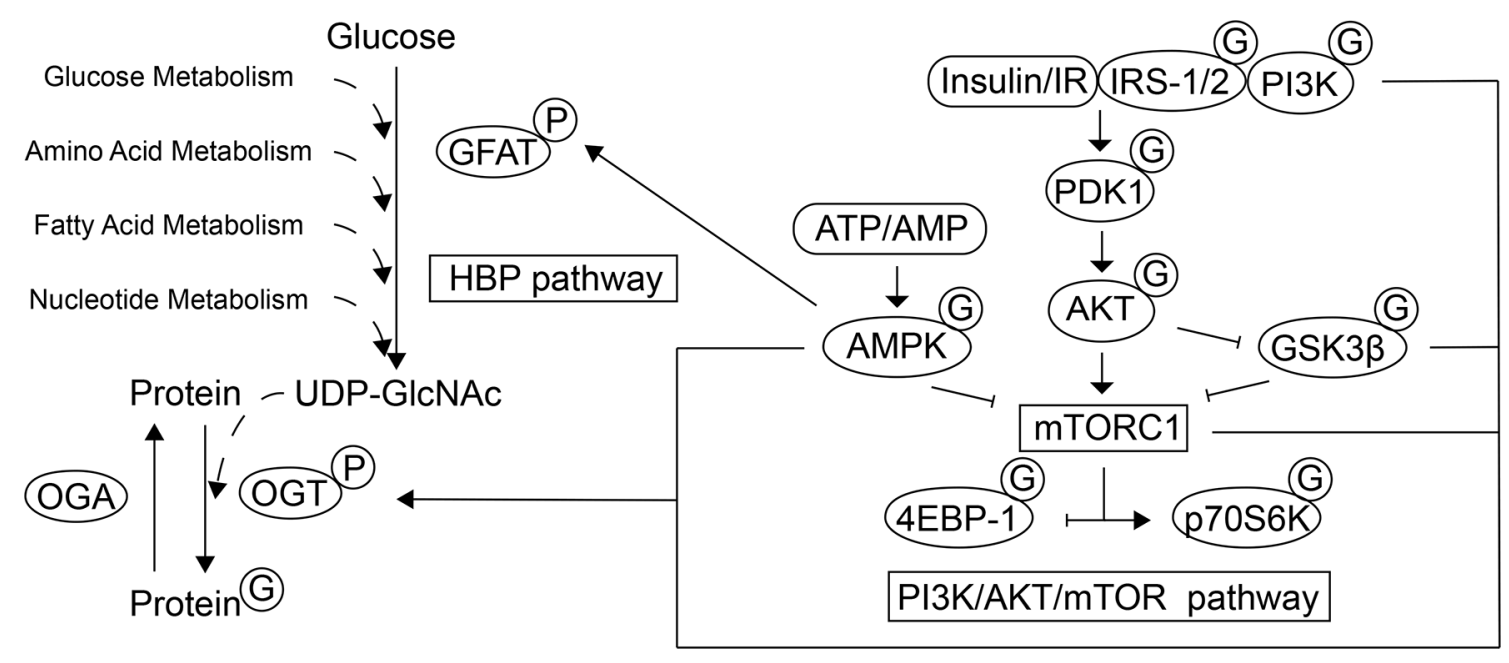

FIGURE 1 | Schematic representation of the interplay between the HBP, mTOR and AMPK pathways. O-GlcNAcylation, as a PTM of a wide variety of nuclear, cytoplasmic, and mitochondrial proteins, participates in various cellular processes. The HBP integrates glucose, fatty acid, amino acid, and nucleotide metabolism to generate the substrate for O-GIcNAcylation, UDP-GIcNAc. GFAT is the rate-limiting step of the HBP and its activity can be regulated by AMPK through phosphorylation. The O-GlcNAc moiety can be transferred to the target proteins and removed by OGT and OGA, respectively. The activity of mTOR and GSK3 $\beta$ can be mediated by the PI3K/AKT signaling pathway and mTORC1 promotes protein synthesis by directly phosphorylating 4E-BP1 and p70S6K. In response to energy state, AMPK also regulates the mTORC1 activity. The localization, activity, and substrate specificity of OGT are regulated through phosphorylation by AMPK, IR/PI3K and GSK3 $\beta$, and the mTOR signaling regulates the expression of OGT. In contrast, several actors of the PI3K/AKT/mTOR signaling pathway have been found to be modified by O-GlcNAcylation, which leads to subsequent biological effects under different physiological conditions. 

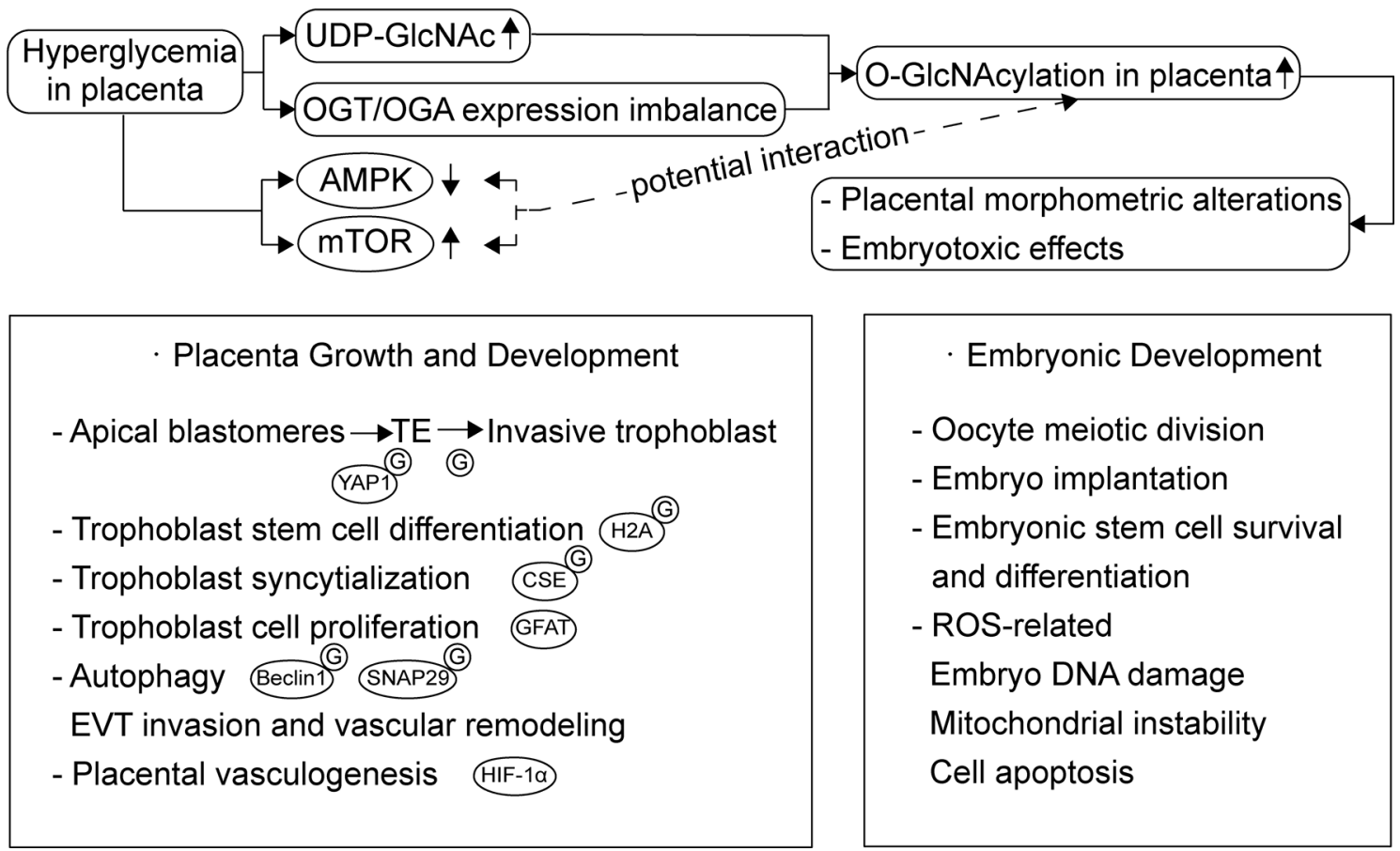

FIGURE 2 Overview of the function of O-GlcNAcylation during placentation and placental development and O-GlcNAcylation dysregulation in placenta exposed to HIP. Besides embryonic development, O-GlcNAcylation also plays a role through all stages of placental development, including trophoblast cell proliferation, differentiation, syncytialization and autophagy. Hyperglycemia increases the glucose flux through HBP and affects placental OGA expression, which leads to increased O-GIcNAcylation accumulation in placenta. These changes may result in placental morphometric alterations and embryotoxic effects. mTOR and AMPK activity altered in HIP and their potential interaction with O-GlcNAcylation needs further studies.

reduced by AMPK activation to prevent adverse effects (59). Moreover, in Human HepG2 cells, it was observed that insulin stimulates the expression and activity of OGT and promotes its targeting to membranes which is dependent on activation of the PI3K pathway (60). Additionally, Kelly et al. (61) recently proved that the inhibition of mTOR signaling decreases the levels of OGT in the human placenta and affects development of the fetal brain. It was also proven in mouse brains that OGT is a substrate of GSK3 $\beta$ and that the phosphorylation of OGT by GSK3 $\beta$ increases OGT activity (62).

In contrast, OGT also acts as a nutrient sensor and regulates diverse cellular signaling pathways based on the metabolic status of cells by sensing glucose levels via UDPGlcNAc concentrations and responding by dynamically $\mathrm{O}-$ GlcNAcylating proteins (63). Few studies have investigated the direct effects of O-GlcNAcylation on the PI3K/AKT/mTOR signaling pathway and its subsequent biological effects under physiological conditions. Under different disease states, OGlcNAcylation has different activation/suppression effects on this signaling pathway $(53,54)$. Studies in the pancreas, liver, and skeletal muscle under diabetic conditions show that increased O-GlcNAcylation downregulates AKT and IRS-1 activity and inhibits the IRS-1/PI3K interaction. This leads to pancreatic $\beta$ cell apoptosis, reduced glucose absorption through the downregulation of insulin-stimulated translocation of glucose transporter 4 (GLUT4) to the plasma membrane, and decreased gluconeogenesis through the regulation of GSK3 $\beta$, which in turn contributes to blood glucose retention (64-69). The expression and activity of GLUTs in the placenta, which mediates maternal-fetal glucose transport, are also changed in HIP, but the influence of hyperglycemia has not been definitively concluded (70). Whereas GLUT1 was identified as the primary transporter in the placenta, James-Allan et al. demonstrated that (71) maternal insulin promotes GLUT4 trafficking to the fetalfacing basal plasma membrane of the STB. Moreover, during the entire process of gestation, the increase in the expression of GLUT4 meets the increased fetal nutrient demand and supports fetal growth. Further studies on skeletal muscle and adipose tissue proposed that GLUT4 could be directly O-GlcNAc modified, which might alter the translocation and transporter ability of GLUT4 (72). And Buller et al. found that basal glucose uptake and GLUT1 expression in rat LEF cell lines are inhibited by GSK3/TSC2/mTOR pathway (73). Whether OGlcNAcylation can influence glucose uptake via direct modifications or the indirect regulation of GLUTs needs further investigation. The increase in protein O-GlcNAcylation in target tissues of diabetic patients might contribute to the maintenance of the pathological status of PI3K/AKT-mediated insulin resistance and could explain diabetic complications and adverse pregnancy outcomes $(3,74)$. O-GlcNAcylation of 
proteins could enhance the sensitivity of the PI3K/AKT/mTOR signaling pathway to nutrients. In addition, metformin, a potentially effective drug that might improve pregnancy outcomes for HIP, has been proposed to causes the upstream activation of AMPK, resulting in the inhibition of mTOR signaling in the placenta (75-79). It has been proven that metformin reduces the levels of OGT and O-GlcNAcylation and reverses the decreased phosphorylation level of AMPK cause by O-GlcNAc modification in cervical cancer cells. Therefore, further exploration of the possible O-GlcNAcylationrelated mechanisms of metformin treatment in placentas exposed to hyperglycemia is required (80).

There seems to be a complex dynamic relationship between these three pathways, and their dynamic changes and interactions may explain the changes in placental nutrient transport in the presence of HIP.

\section{INFLAMMATORY REACTIONS}

Hyperglycemia leads to increased expression of proinflammatory cytokines, such as IL-6 and TNF- $\alpha$, which impairs placental functions (81). The transcriptional activity of $\mathrm{NF}-\kappa \mathrm{B}$, a nuclear factor inducing the expression of these proinflammatory cytokines, is regulated not only by phosphorylation and acetylation, but also by site-specific $\mathrm{O}$ GlcNAcylation (82). Studies on the placenta of hyperglycemic rats show that non-classical activation of NF- $\mathrm{KB}$ is elicited by $\mathrm{O}-$ GlcNAcylation and that the p65 subunit is the main target for OGlcNAcylation. After O-GlcNAcylation, NF- $\kappa \mathrm{B}$ showed higher nuclear translocation and transcriptional activity, which may explain why $\mathrm{NF}-\kappa \mathrm{B}$ activity increases sustainably under hyperglycemic conditions $(82,83)$. In addition to the $\mathrm{O}$ GlcNAcylation of NF- $\kappa B$, Pathak et al. (84) determined that the activation of transforming growth factor (TGF)- $\beta$-activated kinase 1 (TAK1) needs the O-GlcNAcylation of TAK1-binding protein 1 (TAB1) to activate $\mathrm{NF}-\kappa \mathrm{B}$ and finally lead to the production of IL- 6 and TNF- $\alpha$ in IL-1R HEK293 cells. However, O-GlcNAcylation can also be a negative regulator of $\mathrm{NF}-\kappa \mathrm{B}$ activity. According to a study in rat aortic smooth muscle cells, O-GlcNAc modification of NF- $\mathrm{B}$ p 65 inhibited TNF- $\alpha-$ induced inflammatory mediator expression (85).

Currently, studies associated with O-GlcNAcylation of transcription factors, especially those related to inflammation are limited. A study on cardiac fibrosis caused by diabetes mellitus (86) revealed that hyperglycemia enhanced OGlcNAcylation of transcription factor Sp1. This modification increased its transcriptional activity, and promoted the expression of transforming growth factor $\beta 1$ (TGF- $\beta 1$ ) and fibrosis-related proteins such as collagen in cardiac fibroblasts. In the placenta, O-GlcNAcylation of $\mathrm{Sp} 1$ possibly interrupted the interaction of $\mathrm{Sp} 1$ with its cooperative factor to reduce its transcription (87).

Moreover, macrophages, called Hofbauer cells in the placenta, play key roles in chronic inflammatory processes, and long-term exposure to hyperglycemia causes macrophages to exhibit a pro-inflammatory phenotype (88). It has been recently shown in mouse bone marrow-derived macrophages (BMMs) that enhanced UDP-GlcNAc generation caused by increased HBP activity is a trait of M2 macrophages (89). However, there has been no specific study of O-GlcNAcylation in Hofbauer cells to date. Further, the few studies using different macrophage cell models that have evaluated the effect of O-GlcNAcylation on macrophage function report conflicting results. One study reported that O-GlcNAcylation promotes antiviral innate immunity and inflammatory responses in BMMs (90). Another study based on THP-1 cells and mouse peritoneal macrophages revealed that $\mathrm{O}$ GlcNAcylation suppresses innate immune activation and necroptosis of macrophages (91). Additionally, OGlcNAcylation was also proposed to attenuate inflammatory processes in macrophages induced by LPS which was observed in RAW264.7 cells, BMMs and peritoneal mouse macrophages, as well as human monocyte-derived macrophages (92). Yang et al. (93) indicated that overnutrition stimulates O-GlcNAc signaling in macrophages of a mouse model of diet-induced obesity. Further, the activation of O-GlcNAc signaling has a suppressive effect on macrophage proinflammatory activation

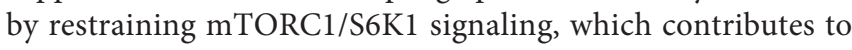
whole-body metabolic homeostasis. These conflicting observations in macrophages might be related to tissue residency or $\mathrm{M} 1 / \mathrm{M} 2$ polarization, and prompt further research on Hofbauer cells is required.

O-GlcNAcylation may be a two-sided modulator of inflammation (94-96). Transcription factors and functional proteins may be modified in different cell types, stimulation conditions, and nutritional states, which may affect their activities and initiate pro-inflammatory or anti-inflammatory functions. The specific role of O-GlcNAcylation in HIP requires further exploration.

\section{CONCLUSIONS}

In summary, O-GlcNAcylation in the placental tissues of women with HIP plays an important role in placental development, nutrition sensing, and inflammatory response, and influences near- and long-term development of offspring. However, there are only a few relevant studies on the influence of $\mathrm{O}$ GlcNAcylation on placental function. It is a process that has not been fully understood, particularly with regard to the regulation of transcription factors, intracellular signal transduction, and epigenetic modifications. As techniques to identify O-GlcNAcylation are increasingly being developed (97-101), further localization and quantitative analyses of OGlcNAcylation in placental tissues exposed to hyperglycemia are required. This will facilitate the analysis of the effect of $\mathrm{O}$ GlcNAcylation on the biological functions of placenta, as well as to understand the mechanistic details of the effect of maternal hyperglycemia on the development of offspring, particularly in relation to abnormalities in maternal-fetal nutrition transport and metabolism. 


\section{AUTHOR CONTRIBUTIONS}

JN and HY wrote the manuscript. All authors contributed to the article and approved the submitted version.

\section{REFERENCES}

1. Hod M, Kapur A, Sacks DA, Hadar E, Agarwal M, Di Renzo GC, et al. The International Federation of Gynecology and Obstetrics (FIGO) Initiative on Gestational Diabetes Mellitus: A Pragmatic Guide for Diagnosis, Management, and Care. Int J Gynecol Obstet (2015) 131:S173-211. doi: 10.1016/s0020-7292(15)30033-3

2. Wei Y, Xu Q, Yang H, Yang Y, Wang L, Chen H, et al. Preconception Diabetes Mellitus and Adverse Pregnancy Outcomes in Over 6.4 Million Women: A Population-Based Cohort Study in China. PloS Med (2019) 16: e1002926. doi: 10.1371/journal.pmed.1002926

3. Sun Y-Y, Juan J, Xu Q-Q, Su R-N, Hirst JE, Yang H-X. Increasing Insulin Resistance Predicts Adverse Pregnancy Outcomes in Women With Gestational Diabetes Mellitus. J Diabetes (2020) 12:438-46. doi: 10.1111/ 1753-0407.13013

4. Li S, Yang H. Relationship Between Advanced Glycation End Products and Gestational Diabetes Mellitus. J Matern Fetal Neonatal Med (2019) 32:27839. doi: 10.1080/14767058.2018.1449201

5. Li H, Dong A, Lv X. Advanced Glycation End Products and Adipocytokines and Oxidative Stress in Placental Tissues of Pregnant Women With Gestational Diabetes Mellitus. Exp Ther Med (2019) 18:685-91. doi: 10.3892/etm.2019.7623

6. Plows JF, Stanley JL, Baker PN, Reynolds CM, Vickers MH. The Pathophysiology of Gestational Diabetes Mellitus. Int J Mol Sci (2018) 19:3342. doi: 10.3390/ijms19113342

7. Yang X, Qian K. Protein O-GlcNAcylation: Emerging Mechanisms and Functions. Nat Rev Mol Cell Biol (2017) 18:452-65. doi: 10.1038/ nrm.2017.22

8. Dela Justina V, Dos Passos Junior RR, Bressan AF, Tostes RC, Carneiro FS, Soares TS, et al. O-Linked N-acetyl-glucosamine Deposition in Placental Proteins Varies According to Maternal Glycemic Levels. Life Sci (2018) 205:18-25. doi: 10.1016/j.lfs.2018.05.013

9. Yao AY, Tang HY, Wang Y, Feng MF, Zhou RL. Inhibition of the Activating Signals in NK92 Cells by Recombinant GST-sHLA-G1a Chain. Cell Res (2004) 14:155-60. doi: 10.1038/sj.cr.7290215

10. Bale TL. Epigenetic and Transgenerational Reprogramming of Brain Development. Nat Rev Neurosci (2015) 16:332-44. doi: 10.1038/nrn3818

11. Wu D, Cai Y, Jin J. Potential Coordination Role Between O-GlcNAcylation and Epigenetics. Protein Cell (2017) 8:713-23. doi: 10.1007/s13238-0170416-4

12. Gao Y, Wells L, Comer FI, Parker GJ, Hart GW. Dynamic O-glycosylation of Nuclear and Cytosolic Proteins: Cloning and Characterization of a Neutral, Cytosolic beta-N-acetylglucosaminidase From Human Brain. J Biol Chem (2001) 276:9838-45. doi: 10.1074/jbc.M010420200

13. Howerton CL, Morgan CP, Fischer DB, Bale TL. O-GlcNAc Transferase (OGT) as a Placental Biomarker of Maternal Stress and Reprogramming of CNS Gene Transcription in Development. Proc Natl Acad Sci USA (2013) 110:5169-74. doi: 10.1073/pnas.1300065110

14. Chen Y, Zhao X, Wu H. Metabolic Stress and Cardiovascular Disease in Diabetes Mellitus: The Role of Protein O-GlcNAc Modification. Arterioscler Thromb Vasc Biol (2019) 39:1911-24. doi: 10.1161/ATVBAHA.119.312192

15. Lima VV, Dela Justina V, Dos Passos RR Jr, Volpato GT, Souto PCS, San Martin S, et al. O-GlcNAc Modification During Pregnancy: Focus on Placental Environment. Front Physiol (2018) 9:1263. doi: 10.3389/ fphys.2018.01263

16. Chi F, Sharpley MS, Nagaraj R, Roy SS, Banerjee U. Glycolysis-Independent Glucose Metabolism Distinguishes TE From ICM Fate During Mammalian Embryogenesis. Dev Cell (2020) 53:9-26.e4. doi: 10.1016/j.devcel. 2020.02 .015

\section{FUNDING}

This work was supported by the National Natural Science Foundation of China (81830044).

17. Ruane PT, Tan CMJ, Adlam DJ, Kimber SJ, Brison DR, Aplin JD, et al Protein O-GlcNAcylation Promotes Trophoblast Differentiation At Implantation. Cells (2020) 9:2246. doi: 10.3390/cells9102246

18. Hirosawa M, Hayakawa K, Yoneda C, Arai D, Shiota H, Suzuki T, et al. Novel O-GlcNAcylation on Ser(40) of Canonical H2A Isoforms Specific to Viviparity. Sci Rep (2016) 6:31785. doi: 10.1038/srep31785

19. Liu J, Shao X, Qin W, Zhang Y, Dang F, Yang Q, et al. Quantitative Chemoproteomics Reveals O-GlcNAcylation of Cystathionine $\gamma$-Lyase (CSE) Represses Trophoblast Syncytialization. Cell Chem Biol (2021) S2451-9456(21)00050-7. doi: 10.1016/j.chembiol.2021.01.024

20. Wen HY, Abbasi S, Kellems RE, Xia Y. mTOR: A Placental Growth Signaling Sensor. Placenta (2005) 26 Suppl A:S63-9. doi: 10.1016/j.placenta.2005.02.004

21. Zhang Q, Na Q, Song W. Moderate Mammalian Target of Rapamycin Inhibition Induces Autophagy in HTR8/SVneo Cells Via O-linked $\beta-\mathrm{N}$ acetylglucosamine Signaling. J Obstet Gynaecol Res (2017) 43:1585-96. doi: $10.1111 /$ jog. 13410

22. He MY, Wang G, Han SS, Jin Y, Li H, Wu X, et al. Nrf2 Signalling and Autophagy Are Involved in Diabetes Mellitus-Induced Defects in the Development of Mouse Placenta. Open Biol (2016) 6:160064. doi: 10.1098/ rsob. 160064

23. Ji L, Chen Z, Xu Y, Xiong G, Liu R, Wu C, et al. Systematic Characterization of Autophagy in Gestational Diabetes Mellitus. Endocrinology (2017) 158:2522-32. doi: 10.1210/en.2016-1922

24. Nakashima A, Tsuda S, Kusabiraki T, Aoki A, Ushijima A, Shima T, et al Current Understanding of Autophagy in Pregnancy. Int J Mol Sci (2019) 20:2342. doi: 10.3390/ijms20092342

25. Pantaleon M, Steane SE, McMahon K, Cuffe JSM, Moritz KM. Placental OGlcNAc-Transferase Expression and Interactions With the Glucocorticoid Receptor Are Sex Specific and Regulated by Maternal Corticosterone Exposure in Mice. Sci Rep (2017) 7:2017. doi: 10.1038/s41598-017-01666-8

26. Howerton CL, Bale TL. Targeted Placental Deletion of OGT Recapitulates the Prenatal Stress Phenotype Including Hypothalamic Mitochondrial Dysfunction. Proc Natl Acad Sci USA (2014) 111:9639-44. doi: 10.1073/ pnas. 1401203111

27. Cowell W, Deyssenroth M, Chen J, Wright RJ. Maternal Stress in Relation to Sex-Specific Expression of Placental Genes Involved in Nutrient Transport, Oxygen Tension, Immune Response, and the Glucocorticoid Barrier. Placenta (2020) 96:19-26. doi: 10.1016/j.placenta.2020.05.004

28. Retnakaran R, Kramer CK, Ye C, Kew S, Hanley AJ, Connelly PW, et al. Fetal Sex and Maternal Risk of Gestational Diabetes Mellitus: The Impact of Having a Boy. Diabetes Care (2015) 38:844-51. doi: 10.2337/dc14-2551

29. Jaskolka D, Retnakaran R, Zinman B, Kramer CK. Sex of the Baby and Risk of Gestational Diabetes Mellitus in the Mother: A Systematic Review and Meta-Analysis. Diabetologia (2015) 58:2469-75. doi: 10.1007/s00125-0153726-1

30. Yang YR, Jang H-J, Lee YH, Kim IS, Lee H, Ryu SH, et al. O-GlcNAc Cycling Enzymes Control Vascular Development of the Placenta by Modulating the Levels of HIF-1 $\alpha$. Placenta (2015) 36:1063-8. doi: 10.1016/ j.placenta.2015.08.001

31. Makwana V, Ryan P, Patel B, Dukie SA, Rudrawar S. Essential Role of OGlcNAcylation in Stabilization of Oncogenic Factors. Biochim Biophys Acta Gen Subj (2019) 1863:1302-17. doi: 10.1016/j.bbagen.2019.04.002

32. Dela Justina V, Priviero F, Dos Passos RR Jr, Webb RC, Lima VV, Giachini FR. O-GlcNAc Impairs Endothelial Function in Uterine Arteries From Virgin But Not Pregnant Rats: The Role of GSK3ß. Eur J Pharmacol (2020) 880:173133. doi: 10.1016/j.ejphar.2020.173133

33. Sawy NAE, Alkushi AG. Histomorphological Study of Placenta in Gestational Diabetes Mellitus. Int J Morphol (2018) 36:687-92. doi: 10.4067/S0717-95022018000200687 
34. Nagy T, Fisi V, Frank D, Kátai E, Nagy Z, Miseta A. Hyperglycemia-Induced Aberrant Cell Proliferation; A Metabolic Challenge Mediated by Protein OGlcNAc Modification. Cells (2019) 8:999. doi: 10.3390/cells8090999

35. Brown HM, Green ES, Tan TCY, Gonzalez MB, Rumbold AR, Hull ML, et al. Periconception Onset Diabetes Is Associated With Embryopathy and Fetal Growth Retardation, Reproductive Tract Hyperglycosylation and Impaired Immune Adaptation to Pregnancy. Sci Rep (2018) 8:2114. doi: 10.1038/ s41598-018-19263-8

36. Kim G, Cao L, Reece EA, Zhao Z. Impact of Protein O-GlcNAcylation on Neural Tube Malformation in Diabetic Embryopathy. Sci Rep (2017) 7:11107. doi: 10.1038/s41598-017-11655-6

37. Na H-J, Akan I, Abramowitz LK, Hanover JA. Nutrient-Driven OGlcNAcylation Controls DNA Damage Repair Signaling and Stem/ Progenitor Cell Homeostasis. Cell Rep (2020) 31:107632. doi: 10.1016/ j.celrep.2020.107632

38. Muha V, Authier F, Szoke-Kovacs Z, Johnson S, Gallagher J, McNeilly A, et al. Loss of O-GlcNAcase Catalytic Activity Leads to Defects in Mouse Embryogenesis. J Biol Chem (2021) 296:100439. doi: 10.1016/ j.jbc.2021.100439

39. Pantaleon M, Tan HY, Kafer GR, Kaye PL. Toxic Effects of Hyperglycemia are Mediated by the Hexosamine Signaling Pathway and O-Linked Glycosylation in Early Mouse Embryos. Biol Reprod (2010) 82:751-8. doi: 10.1095/biolreprod.109.076661

40. Parween S, Varghese DS, Ardah MT, Prabakaran AD, Mensah-Brown E, Emerald BS, et al. Higher O-GlcNAc Levels Are Associated With Defects in Progenitor Proliferation and Premature Neuronal Differentiation During Human Embryonic Cortical Neurogenesis. Front Cell Neurosci (2017) 11:415. doi: 10.3389/fncel.2017.00415

41. Gabory A, Roseboom TJ, Moore T, Moore LG, Junien C. Placental Contribution to the Origins of Sexual Dimorphism in Health and Diseases: Sex Chromosomes and Epigenetics. Biol Sex Differ (2013) 4:5. doi: $10.1186 / 2042-6410-4-5$

42. Hart B, Morgan E, Alejandro EU. Nutrient Sensor Signaling Pathways and Cellular Stress in Fetal Growth Restriction. J Mol Endocrinol (2019) 62: R155-65. doi: 10.1530/JME-18-0059

43. Wullschleger S, Loewith R, Hall MN. TOR Signaling in Growth and Metabolism. Cell (2006) 124:471-84. doi: 10.1016/j.cell.2006.01.016

44. Zhang QX, Na Q, Song W. Altered Expression of mTOR and Autophagy in Term Normal Human Placentas. Rom J Morphol Embryol (2017) 58:517-26.

45. Shao X, Cao G, Chen D, Liu J, Yu B, Liu M, et al. Placental Trophoblast Syncytialization Potentiates Macropinocytosis Via mTOR Signaling to Adapt to Reduced Amino Acid Supply. Proc Natl Acad Sci USA (2021) 118:e2017092118. doi: 10.1073/pnas.2017092118

46. Laplante M, Sabatini DM. mTOR Signaling in Growth Control and Disease. Cell (2012) 149:274-93. doi: 10.1016/j.cell.2012.03.017

47. Manning BD, Toker A. AKT/PKB Signaling: Navigating the Network. Cell (2017) 169:381-405. doi: 10.1016/j.cell.2017.04.001

48. Ma XM, Blenis J. Molecular Mechanisms of mTOR-mediated Translational Control. Nat Rev Mol Cell Biol (2009) 10:307-18. doi: 10.1038/nrm2672

49. Golick L, Han Y, Kim Y, Park SW. BRD7 Regulates the Insulin-Signaling Pathway by Increasing Phosphorylation of GSK3 $\beta$. Cell Mol Life Sci (2018) 75:1857-69. doi: 10.1007/s00018-017-2711-x

50. Inoki K, Ouyang H, Zhu T, Lindvall C, Wang Y, Zhang X, et al. TSC2 Integrates Wnt and Energy Signals Via a Coordinated Phosphorylation by AMPK and GSK3 to Regulate Cell Growth. Cell (2006) 126:955-68. doi: 10.1016/j.cell.2006.06.055

51. Liu X, Chhipa RR, Pooya S, Wortman M, Yachyshin S, Chow LML, et al. Discrete Mechanisms of mTOR and Cell Cycle Regulation by AMPK Agonists Independent of AMPK. Proc Natl Acad Sci USA (2014) 111: E435-44. doi: 10.1073/pnas.1311121111

52. Very N, Steenackers A, Dubuquoy C, Vermuse J, Dubuquoy L, Lefebvre T, et al. Cross Regulation Between mTOR Signaling and O-GlcNAcylation. J Bioenerg Biomembr (2018) 50:213-22. doi: 10.1007/s10863-018-9747-y

53. Very N, Vercoutter-Edouart AS, Lefebvre T, Hardiville S, El Yazidi-Belkoura I. Cross-Dysregulation of O-GlcNAcylation and PI3K/AKT/mTOR Axis in Human Chronic Diseases. Front Endocrinol (Lausanne) (2018) 9:602. doi: $10.3389 /$ fendo.2018.00602
54. Shi J, Wu S, Dai C-I, Li Y, Grundke-Iqbal I, Iqbal K, et al. Diverse Regulation of AKT and GSK-3 $\beta$ by O-GlcNAcylation in Various Types of Cells. FEBS Lett (2012) 586:2443-50. doi: 10.1016/j.febslet.2012.05.063

55. Tsai K, Tullis B, Jensen T, Graff T, Reynolds P, Arroyo J. Differential Expression of mTOR Related Molecules in the Placenta From Gestational Diabetes Mellitus (GDM), Intrauterine Growth Restriction (IUGR) and Preeclampsia Patients. Reprod Biol (2021) 21:100503. doi: 10.1016/ j.repbio.2021.100503

56. Hulme CH, Stevens A, Dunn W, Heazell AEP, Hollywood K, Begley P, et al. Identification of the Functional Pathways Altered by Placental Cell Exposure to High Glucose: Lessons From the Transcript and Metabolite Interactome. Sci Rep (2018) 8:5270. doi: 10.1038/s41598-018-22535-y

57. Nguyen-Ngo C, Jayabalan N, Salomon C, Lappas M. Molecular Pathways Disrupted by Gestational Diabetes Mellitus. J Mol Endocrinol (2019) 63: R51-72. doi: 10.1530/JME-18-0274

58. Gélinas R, Mailleux F, Dontaine J, Bultot L, Demeulder B, Ginion A, et al. AMPK Activation Counteracts Cardiac Hypertrophy by Reducing OGlcNAcylation. Nat Commun (2018) 9:374. doi: 10.1038/s41467-01702795-4

59. Gélinas R, Dontaine J, Horman S, Beauloye C, Bultot L, Bertrand L. AMPActivated Protein Kinase and O-GlcNAcylation, Two Partners Tightly Connected to Regulate Key Cellular Processes. Front Endocrinol (2018) 9:519. doi: 10.3389/fendo.2018.00519

60. Perez-Cervera Y, Dehennaut V, Aquino Gil M, Guedri K, Solórzano Mata CJ, Olivier-Van Stichelen S, et al. Insulin Signaling Controls the Expression of O-GlcNAc Transferase and its Interaction With Lipid Microdomains. FASEB J (2013) 27:3478-86. doi: 10.1096/fj.12-217984

61. Kelly AC, Kramer A, Rosario FJ, Powell TL, Jansson T. Inhibition of Mechanistic Target of Rapamycin Signaling Decreases Levels of OGlcNAc Transferase and Increases Serotonin Release in the Human Placenta. Clin Sci (London Engl 1979) (2020) 134:3123-36. doi: 10.1042/ CS20201050

62. Kaasik K, Kivimäe S, Allen JJ, Chalkley RJ, Huang Y, Baer K, et al. Glucose Sensor O-GlcNAcylation Coordinates With Phosphorylation to Regulate Circadian Clock. Cell Metab (2013) 17:291-302. doi: 10.1016/ j.cmet.2012.12.017

63. Lazarus MB, Nam Y, Jiang J, Sliz P, Walker S. Structure of Human OGlcNAc Transferase and its Complex With a Peptide Substrate. Nature (2011) 469:564-7. doi: 10.1038/nature09638

64. Whelan SA, Dias WB, Thiruneelakantapillai L, Lane MD, Hart GW. Regulation of Insulin Receptor Substrate 1 (IRS-1)/AKT Kinase-Mediated Insulin Signaling by O-Linked beta- $\mathrm{N}$-acetylglucosamine in 3T3-L1 Adipocytes. J Biol Chem (2010) 285:5204-11. doi: 10.1074/jbc.M109.077818

65. Park SY, Ryu J, Lee W. O-GlcNAc Modification on IRS-1 and Akt2 by PUGNAc Inhibits Their Phosphorylation and Induces Insulin Resistance in Rat Primary Adipocytes. Exp Mol Med (2005) 37:220-9. doi: 10.1038/ emm.2005.30

66. Soesanto YA, Luo B, Jones D, Taylor R, Gabrielsen JS, Parker G, et al. Regulation of Akt Signaling by O-GlcNAc in Euglycemia. American Journal of Physiology. Endocrinol Metab (2008) 295:E974-80. doi: 10.1152/ ajpendo.90366.2008

67. Parker GJ, Lund KC, Taylor RP, McClain DA. Insulin Resistance of Glycogen Synthase Mediated by O-Linked N-Acetylglucosamine. J Biol Chem (2003) 278:10022-7. doi: 10.1074/jbc.M207787200

68. Kang E-S, Han D, Park J, Kwak TK, Oh M-A, Lee S-A, et al. O-GlcNAc Modulation At Akt1 Ser473 Correlates With Apoptosis of Murine Pancreatic Beta Cells. Exp Cell Res (2008) 314:2238-48. doi: 10.1016/ j.yexcr.2008.04.014

69. Ruan HB, Singh JP, Li MD, Wu J, Yang X. Cracking the O-GlcNAc Code in Metabolism. Trends Endocrinol Metab (2013) 24:301-9. doi: 10.1016/ j.tem.2013.02.002

70. Stanirowski PJ, Szukiewicz D, Pazura-Turowska M, Sawicki W, Cendrowski K. Placental Expression of Glucose Transporter Proteins in Pregnancies Complicated by Gestational and Pregestational Diabetes Mellitus. Can J Diabetes (2018) 42:209-17. doi: 10.1016/j.jcjd.2017.04.008

71. James-Allan LB, Arbet J, Teal SB, Powell TL, Jansson T. Insulin Stimulates GLUT4 Trafficking to the Syncytiotrophoblast Basal Plasma Membrane in 
the Human Placenta. J Clin Endocrinol Metab (2019) 104:4225-38. doi: 10.1210/jc.2018-02778

72. Bacigalupa ZA, Bhadiadra CH, Reginato MJ. O-GlcNAcylation: Key Regulator of Glycolytic Pathways. J Bioenerg Biomembr (2018) 50:189-98. doi: 10.1007/s10863-018-9742-3

73. Buller CL, Loberg RD, Fan MH, Zhu Q, Park JL, Vesely E, et al. A GSK-3/ TSC2/mTOR Pathway Regulates Glucose Uptake and GLUT1 Glucose Transporter Expression. Am J Physiol Cell Physiol (2008) 295:C836-43. doi: 10.1152/ajpcell.00554.2007

74. Cork GK, Thompson J, Slawson C. Real Talk: The Inter-Play Between the mTOR, AMPK, and Hexosamine Biosynthetic Pathways in Cell Signaling. Front Endocrinol (Lausanne) (2018) 9:522. doi: 10.3389/fendo.2018.00522

75. Grace MR, Dotters-Katz SK, Zhou C, Manuck T, Boggess K, Bae-Jump V. Effect of a High-Fat Diet and Metformin on Placental mTOR Signaling in Mice. AJP Rep (2019) 9:e138-43. doi: 10.1055/s-0039-1683362

76. Feng Y, Yang H. Metformin - a Potentially Effective Drug for Gestational Diabetes Mellitus: A Systematic Review and Meta-Analysis. J Matern Fetal Neonatal Med (2017) 30:1874-81. doi: 10.1080/14767058.2016.1228061

77. Sivalingam VN, Myers J, Nicholas S, Balen AH, Crosbie EJ. Metformin in Reproductive Health, Pregnancy and Gynaecological Cancer: Established and Emerging Indications. Hum Reprod Update (2014) 20:853-68. doi: 10.1093/humupd/dmu037

78. Lindsay RS, Loeken MR. Metformin Use in Pregnancy: Promises and Uncertainties. Diabetologia (2017) 60:1612-9. doi: 10.1007/s00125-0174351-y

79. Jiang S, Teague AM, Tryggestad JB, Jensen ME, Chernausek SD. Role of Metformin in Epigenetic Regulation of Placental Mitochondrial Biogenesis in Maternal Diabetes. Sci Rep (2020) 10:8314. doi: 10.1038/s41598-02065415-0

80. Kim MY, Kim YS, Kim M, Choi MY, Roh GS, Lee DH, et al. Metformin Inhibits Cervical Cancer Cell Proliferation Via Decreased AMPK OGlcNAcylation. Anim Cells Syst (Seoul) (2019) 23:302-9. doi: 10.1080/ 19768354.2019.1614092

81. Kawaharada R, Masuda H, Chen Z, Blough E, Kohama T, Nakamura A. Intrauterine Hyperglycemia-Induced Inflammatory Signalling Via the Receptor for Advanced Glycation End Products in the Cardiac Muscle of the Infants of Diabetic Mother Rats. Eur J Nutr (2018) 57:2701-12. doi: 10.1007/s00394-017-1536-6

82. Yang WH, Park SY, Nam HW, Kim DH, Kang JG, Kang ES, et al. NFkappaB Activation is Associated With its O-GlcNAcylation State Under Hyperglycemic Conditions. Proc Natl Acad Sci USA (2008) 105:17345-50. doi: 10.1073/pnas.0806198105

83. Dela Justina V, Gonçalves JS, de Freitas RA, Fonseca AD, Volpato GT, Tostes RC, et al. Increased O-Linked N-Acetylglucosamine Modification of NF-KB and Augmented Cytokine Production in the Placentas From Hyperglycemic Rats. Inflammation (2017) 40:1773-81. doi: 10.1007/ s10753-017-0620-7

84. Pathak S, Borodkin VS, Albarbarawi O, Campbell DG, Ibrahim A, van Aalten DM. O-GlcNAcylation of TAB1 Modulates TAK1-mediated Cytokine Release. EMBO J (2012) 31:1394-404. doi: 10.1038/emboj.2012.8

85. Xing D, Gong K, Feng W, Nozell SE, Chen Y-F, Chatham JC, et al. OGlcNAc Modification of NFKB p65 Inhibits TNF- $\alpha$-Induced Inflammatory Mediator Expression in Rat Aortic Smooth Muscle Cells. PloS One (2011) 6: e24021. doi: 10.1371/journal.pone.0024021

86. Aguilar H, Fricovsky E, Ihm S, Schimke M, Maya-Ramos L, Aroonsakool N, et al. Role for High-Glucose-Induced Protein O-GlcNAcylation in Stimulating Cardiac Fibroblast Collagen Synthesis. Am J Physiol Cell Physiol (2014) 306:C794-804. doi: 10.1152/ajpcell.00251.2013

87. Lim K, Chang H-I. O-GlcNAc Inhibits Interaction Between Sp1 and Elf-1 Transcription Factors. Biochem Biophys Res Commun (2009) 380:569-74. doi: 10.1016/j.bbrc.2009.01.121
88. Sisino G, Bouckenooghe T, Aurientis S, Fontaine P, Storme L, Vambergue A. Diabetes During Pregnancy Influences Hofbauer Cells, a Subtype of Placental Macrophages, to Acquire a Pro-Inflammatory Phenotype. Biochim Biophys Acta (2013) 1832:1959-68. doi: 10.1016/ j.bbadis.2013.07.009

89. Jha AK, Huang SC-C, Sergushichev A, Lampropoulou V, Ivanova Y, Loginicheva E, et al. Network Integration of Parallel Metabolic and Transcriptional Data Reveals Metabolic Modules That Regulate Macrophage Polarization. Immunity (2015) 42:419-30. doi: 10.1016/ j.immuni.2015.02.005

90. Li T, Li X, Attri KS, Liu C, Li L, Herring LE, et al. O-GlcNAc Transferase Links Glucose Metabolism to MAVS-Mediated Antiviral Innate Immunity. Cell Host Microbe (2018) 24:791-803.e6. doi: 10.1016/j.chom.2018.11.001

91. Li X, Gong W, Wang H, Li T, Attri KS, Lewis RE, et al. O-GlcNAc Transferase Suppresses Inflammation and Necroptosis by Targeting Receptor-Interacting Serine/Threonine-Protein Kinase 3. Immunity (2019) 50:1115. doi: 10.1016/j.immuni.2019.01.007

92. Al-Mukh H, Baudoin L, Bouaboud A, Sanchez-Salgado J-L, Maraqa N, Khair $\mathrm{M}$, et al. Lipopolysaccharide Induces GFAT2 Expression to Promote -Linked $\beta$-Acetylglucosaminylation and Attenuate Inflammation in Macrophages. J Immunol (Baltimore Md 1950) (2020) 205:2499-510. doi: 10.4049/ jimmunol.2000345

93. Yang Y, Li X, Luan HH, Zhang B, Zhang K, Nam JH, et al. OGT Suppresses S6K1-mediated Macrophage Inflammation and Metabolic Disturbance. Proc Natl Acad Sci U S A (2020) 117:16616-25. doi: 10.1073/pnas.1916121117

94. Li Y, Xie M, Men L, Du J. O-GlcNAcylation in Immunity and Inflammation: An Intricate System (Review). Int J Mol Med (2019) 44:363-74. doi: 10.3892/ ijmm.2019.4238

95. Baudoin L, Issad T. O-GlcNAcylation and Inflammation: A Vast Territory to Explore. Front Endocrinol (2014) 5:235. doi: 10.3389/fendo.2014.00235

96. Chang Y-H, Weng C-L, Lin K-I. O-GlcNAcylation and its Role in the Immune System. J Biomed Sci (2020) 27:57. doi: 10.1186/s12929-020-00648-9

97. Qin K, Zhu Y, Qin W, Gao J, Shao X, Wang YL, et al. Quantitative Profiling of Protein O-GlcNAcylation Sites by an Isotope-Tagged Cleavable Linker. ACS Chem Biol (2018) 13:1983-9. doi: 10.1021/acschembio.8b00414

98. Jia C, Zuo Y, Zou Q. O-GlcNAcPRED-II: An Integrated Classification Algorithm for Identifying O-GlcNAcylation Sites Based on Fuzzy Undersampling and a K-means PCA Oversampling Technique. Bioinformatics (Oxford England) (2018) 34:2029-36. doi: 10.1093/ bioinformatics/bty039

99. Worth M, Li H, Jiang J. Deciphering the Functions of Protein OGlcNAcylation With Chemistry. ACS Chem Biol (2017) 12:326-35. doi: 10.1021/acschembio.6b01065

100. Deracinois B, Camoin L, Lambert M, Boyer J-B, Dupont E, Bastide B, et al. OGlcNAcylation Site Mapping by (Azide-Alkyne) Click Chemistry and Mass Spectrometry Following Intensive Fractionation of Skeletal Muscle Cells Proteins. J Proteomics (2018) 186:83-97. doi: 10.1016/j.jprot.2018.07.005

101. Leney AC, Rafie K, van Aalten DMF, Heck AJR. Direct Monitoring of Protein O-GlcNAcylation by High-Resolution Native Mass Spectrometry. ACS Chem Biol (2017) 12:2078-84. doi: 10.1021/acschembio.7b00371

Conflict of Interest: The authors declare that the research was conducted in the absence of any commercial or financial relationships that could be construed as a potential conflict of interest.

Copyright $(2021$ Ning and Yang. This is an open-access article distributed under the terms of the Creative Commons Attribution License (CC BY). The use, distribution or reproduction in other forums is permitted, provided the original author(s) and the copyright owner(s) are credited and that the original publication in this journal is cited, in accordance with accepted academic practice. No use, distribution or reproduction is permitted which does not comply with these terms. 